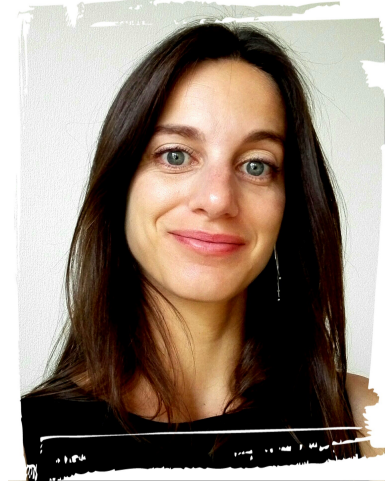

\title{
THE SECOND ME: SEEING THE REAL BODY DURING HUMANOID ROBOT EMBODIMENT PRODUCES AN ILLUSION OF BI-LOCATION
}

by Laura Aymerich-Franch, Damien Petit, Gowrishankar Ganesh, Abderrahmane Kheddar published in Consciousness and cognition, 46

presented by Malte Heyen

Social Robotics Journal Club, 28.07.2017
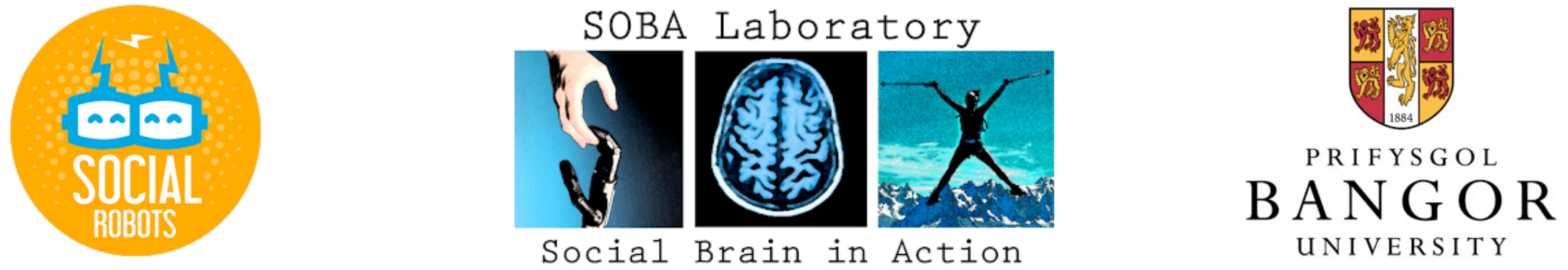


\section{Introduction}

\section{Autoscopic Phenomena:}

- out-of-body experience (OBE)

- autoscopic hallucination

- heautoscopy

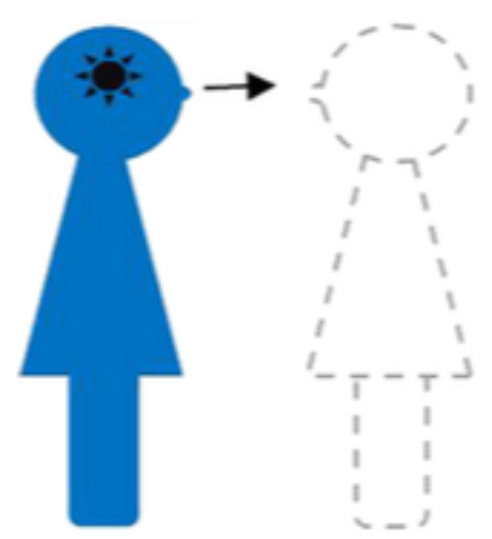

Autoscopic hallucination ("i.e. they see a second own body)

("they feel located outside of the physical body")

("see an illusory double of themselves")

("being split in two selves")

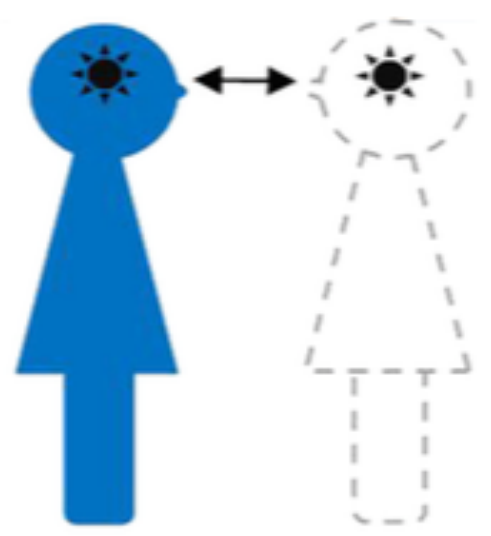

Heautoscopy

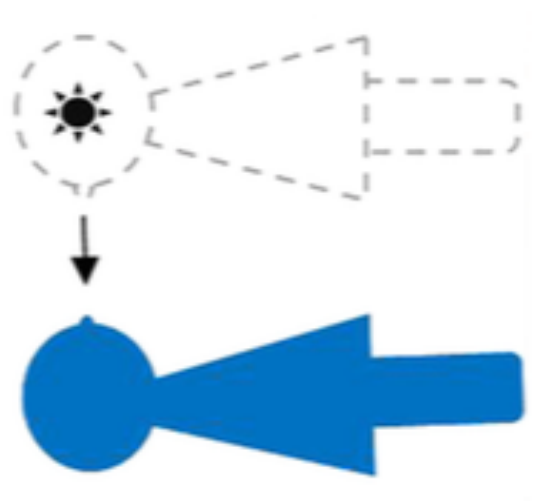

Out-of-body experience 


\section{Introduction}

Autoscopic Phenomena:

- Multisensory integration failure in the TPJ - temporo-parietal junction

\section{Theory-of-mind network}

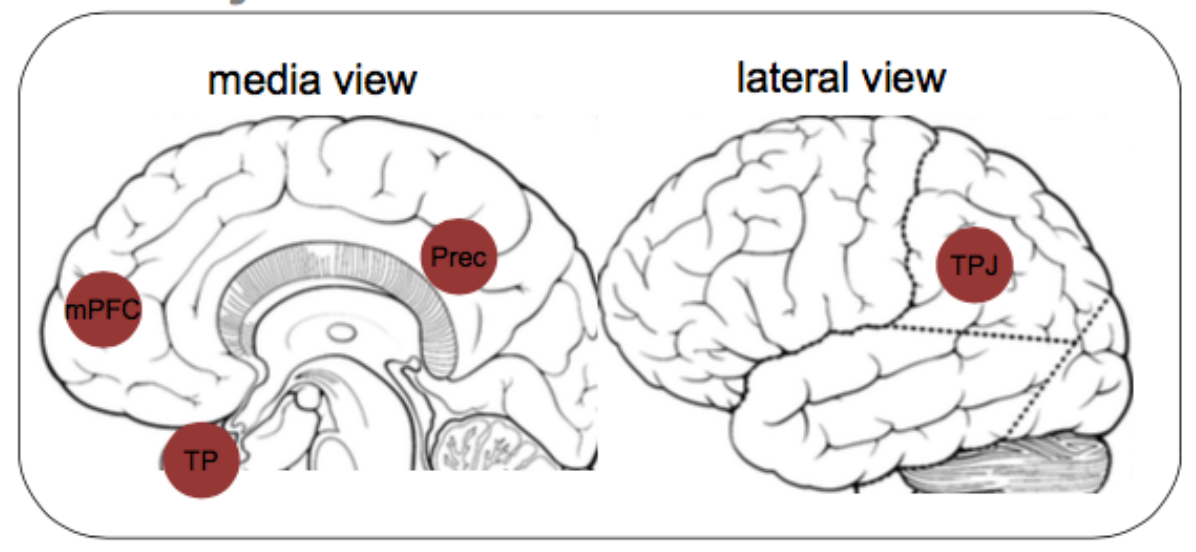

("i.e. they see a second own body)
Interaction between mentalizing and attention reorienting

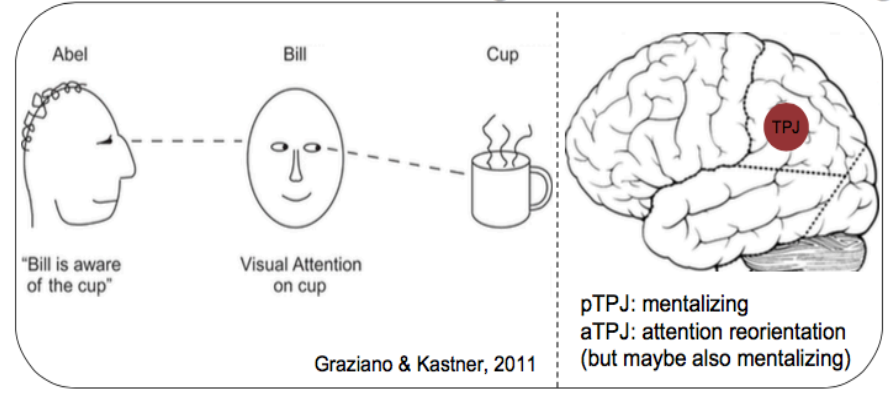

Aim of the study

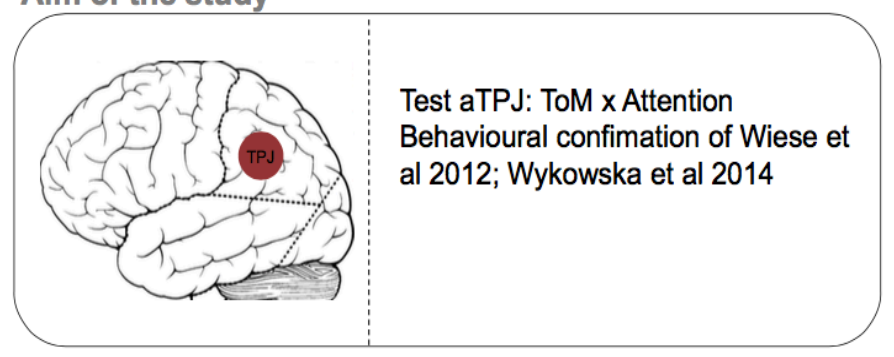

c.f. Journal Club \#5 


\section{Introduction}

\section{Autoscopic Phenomena:}

- Multisensory integration failure in the TPJ - temporo-parietal junction

- Integrates information from the thalamus, the limbic system, the visual, auditory, and somatosensory systems (External and internal)

- Theory of mind network

- Self-other distinction

- moral decision making

- Attention reorientation

- Metalizing or ascription of beliefs 


\section{Aim of the Study}

Mental bi-location? Heautoscopy?

Contradiction in previous work

\section{Embodiment in a non-human avatar?}

i.e. a humanoid Robot

previous work only investigated human-like avatars 


\section{Experimental Setup}
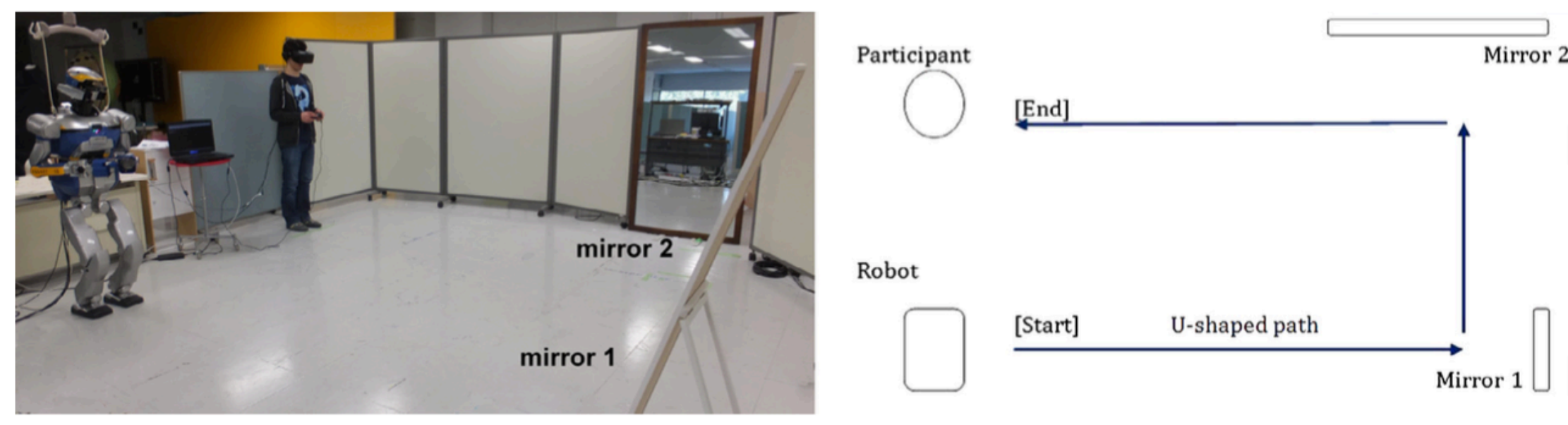

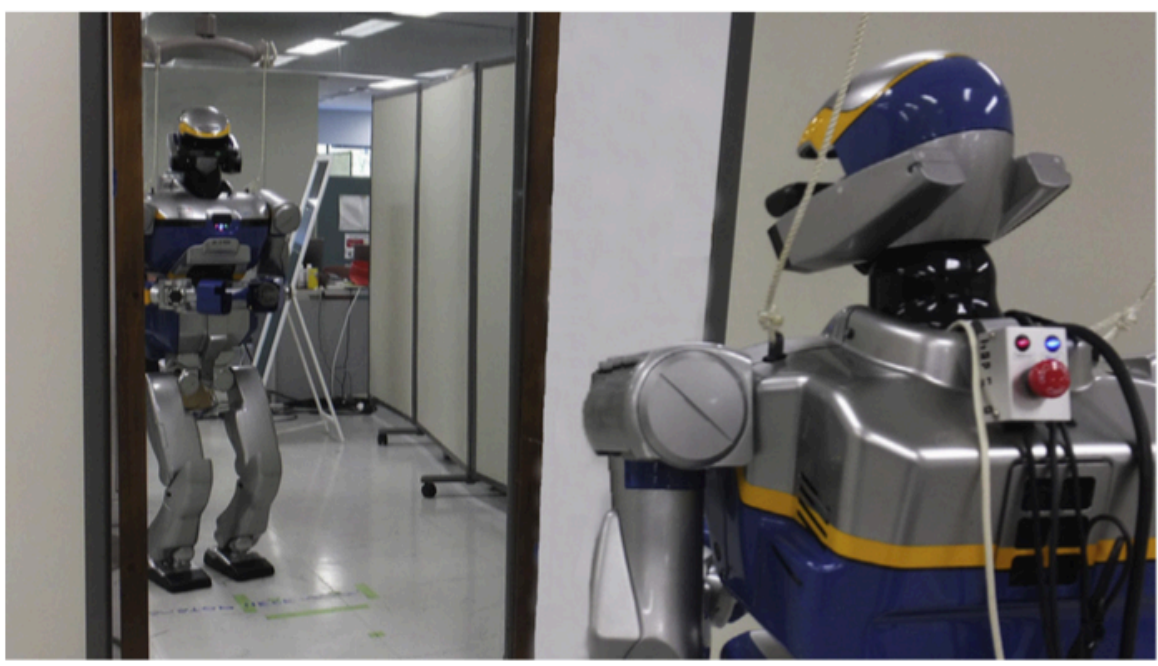

Induction stage

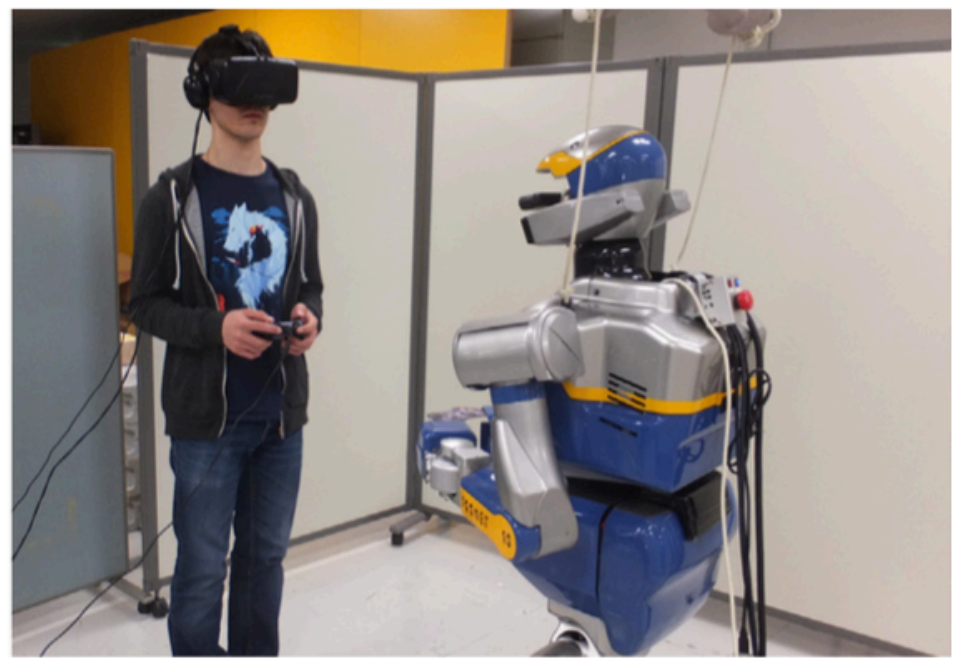

Reduplication stage 


\section{Hypothesis}

- Research questions:

$R Q_{1}$ :

"in what body (real or artificial) individuals perceive self-location and with what body self-identification prevails during humanoid embodiment"?

RQ2:

[Does] "having agency influences the perceived sense of self-location and self-identification during robot embodiment and artificial body reduplication compared to the case when there is no agency"?

- Hypothesis:

$\mathrm{H}_{1 \mathrm{a}}$ :

"participants would feel significantly more embodied in the robot's body during the embodiment process than before starting the experience"

$\mathrm{H}_{1 \mathrm{~b}}$ :

"participants would feel significantly more embodied in the robot's body during the illusion of body reduplication than before starting the experience" 


\section{Experimental Methods/design?}

- Within-subject design

(statistical power, induction in healthy participants, temporal)

- 13 naive participants (7f, $6 \mathrm{~m}$ )

- Initialization -> Induction -> Reduplication

- CR (controlled-robot), NRC (non-controlled-robot)

- bipedal humanoid-looking robot (HRP-2), $154 \mathrm{~cm}, 58 \mathrm{~kg}, 32 \mathrm{df}$

- Oculus Rift Development Kit 2

- stereo headsets with active noise cancellation 


\section{Measures}

- Assessed the score for

- videogame playing (3),

- familiarity with robots (2)

- likeability for humanoid robots (5)

- Embodiment questionnaire (Cronbachs $a=0.94$ )

Kilteni et al., 2012:

- self-location

- body ownership

- agency

- Qualitative questionnaire

- Manipulation check

(did you control the robot? $y / n$; did you see what the robot saw? $y / n$ )

- Demographic information 


\section{Appendix A}

Embodiment questionnaire
Do you feel as if. . . (1.Not at all -7. Very Strongly)
The robot's body was your own body
You were located at the position of the robot
You could use the robot's body to push objects near him if
you wanted

\section{$\underline{\text { Self-location questionnaire }}$}

1.2

When you saw your robotic body reflected in the big mirror, how strongly did you feel. . . (1.Not at all -7 .Very Strongly)

In the robot's body

In the human body

In both bodies at the same time

Swapping your position between the robot's body and the human body several times

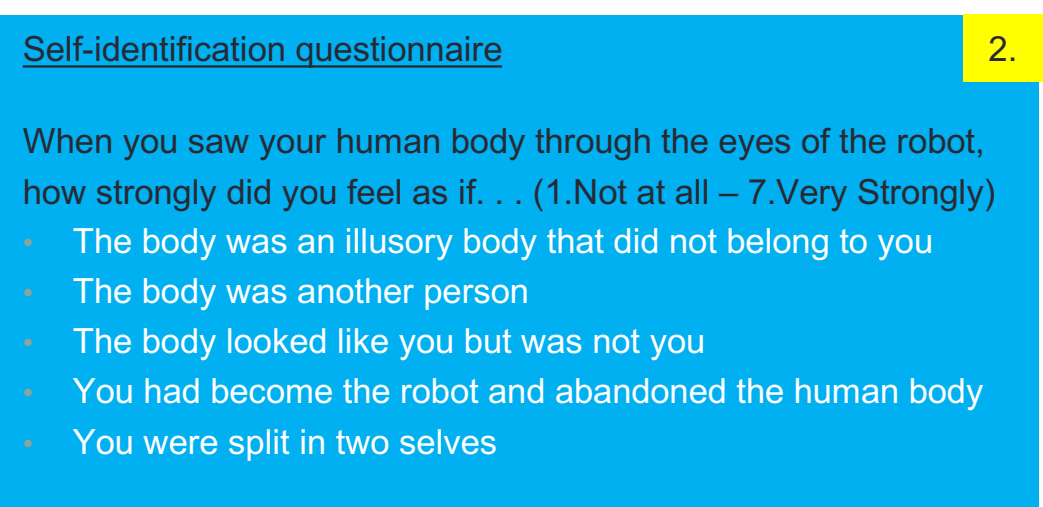

Disembodiment items Qualitative data collection

Please share your thoughts in as much detail as possible:

What did you experience when you saw your robotic body reflected on the mirror? What did you experience when you saw your body through the eyes of the robot? 


\section{Results}

\section{Table B1}

Means and SD for global embodiment before the experiment, during the induction phase, and during the reduplication phase for the controlled robot and noncontrolled robot conditions.

\begin{tabular}{|c|c|c|c|c|c|c|c|}
\hline \multirow[t]{2}{*}{$\mathrm{n}=13$} & \multirow[b]{2}{*}{ Initial score } & \multicolumn{3}{|l|}{ Induction } & \multicolumn{3}{|c|}{ Reduplication } \\
\hline & & Average & $\begin{array}{l}\text { Controlled robot } \\
M(S D)\end{array}$ & $\begin{array}{l}\text { Non-controlled robot } \\
\mathrm{M}(\mathrm{SD})\end{array}$ & Average & $\begin{array}{l}\text { Controlled robot } \\
\mathrm{M}(S D)\end{array}$ & $\begin{array}{l}\text { Non- controlled robot } \\
M(S D)\end{array}$ \\
\hline Embodiment score & $2.86(1.57)$ & $4.45(1.41)$ & $4.59(1.37)$ & $4.31(1.75)$ & $4.03(1.61)$ & $4.46(1.61)$ & $3.58(2.1)$ \\
\hline
\end{tabular}
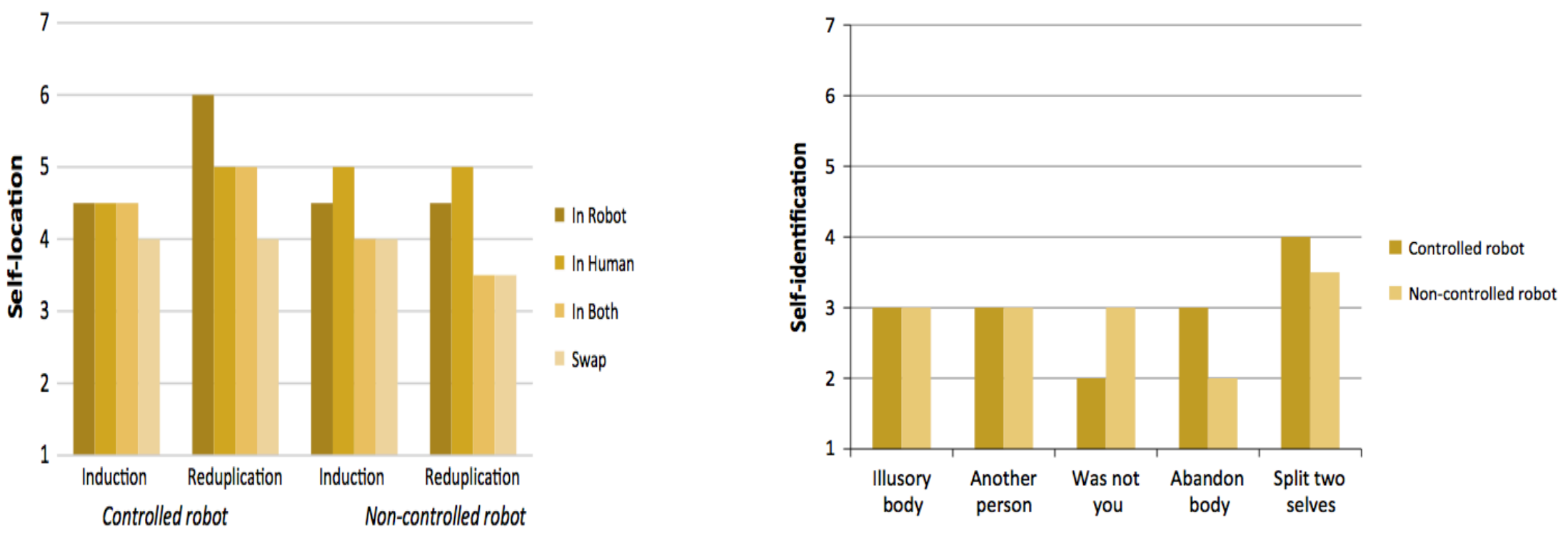

Fig. C1. Reported self-location (median scores) during induction and reduplication in the CR and NCR conditions.

Fig. C2. Median score for self-identification items in the CR and NCR conditions. 


\section{Hypothesis}

- Research questions:

$\mathrm{RQ}_{1}$ :

"in what body (real or artificial) individuals perceive self-location and with what body self-identification prevails during humanoid embodiment"?

RQ2:

[Does] "having agency influences the perceived sense of self-location and self-identification during robot embodiment and artificial body reduplication compared to the case when there is no agency"?

\section{- Hypothesis:}

$\mathrm{H}_{1 a}$ :

"participants would feel significantly more embodied in the robot's body during the embodiment process than before starting the experience"

$\mathrm{H}_{1 \mathrm{~b}}$ :

"participants would feel significantly more embodied in the robot's body during the illusion of body reduplication than before starting the experience" 


\section{Results}

- Hypothesis:

$\mathrm{H}_{1 \mathrm{a}}$ :

"participants would feel significantly more embodied in the robot's body during

the embodiment process than before starting the experience"

- Result:

- the feeling of embodiment into the humanoid robot body was significantly stronger after induction compared to the initial sense of embodiment

- $\mathrm{t}(11)=4.05, p=0.002, \eta^{2}=0.599$, average of all conditions

- $t(11)=3.33, p=0.007, \eta^{2}=0.503$, in the CR condition

- $t(11)=4.28, p=0.001, \eta^{2}=0.625$, in the NCR condition

Table B1

Means and SD for global embodiment before the experiment, during the induction phase, and during the reduplication phase for the controlled robot and noncontrolled robot conditions.

\begin{tabular}{|c|c|c|c|c|c|c|c|}
\hline \multirow[t]{2}{*}{$\mathrm{n}=13$} & \multirow[b]{2}{*}{ Initial score } & \multicolumn{3}{|l|}{ Induction } & \multicolumn{3}{|c|}{ Reduplication } \\
\hline & & Average & $\begin{array}{l}\text { Controlled robot } \\
\mathrm{M}(\mathrm{SD})\end{array}$ & $\begin{array}{l}\text { Non-controlled robot } \\
\mathrm{M}(\mathrm{SD})\end{array}$ & Average & $\begin{array}{l}\text { Controlled robot } \\
\mathrm{M}(\mathrm{SD})\end{array}$ & $\begin{array}{l}\text { Non- controlled robot } \\
M(S D)\end{array}$ \\
\hline Embodiment score & $2.86(1.57)$ & $4.45(1.41)$ & $4.59(1.37)$ & $4.31(1.75)$ & $4.03(1.61)$ & $4.46(1.61)$ & $3.58(2.1)$ \\
\hline
\end{tabular}




\section{Results}

- Hypothesis:

$\mathrm{H}_{1 \mathrm{~b}}$ :

"participants would feel significantly more embodied in the robot's body during the illusion of body reduplication than before starting the experience"

\section{- Result:}

- the feeling of embodiment in the robot's body was significantly higher after reduplication compared to the initial sense of embodiment

- $\mathrm{t}(11)=3.02, \mathrm{p}=0.012, \eta^{2}=0.454$, average of all conditions

- $\mathrm{t}(11)=-3.33, \mathrm{p}=0.017, \eta^{2}=0.418$, in the CR condition

- $\mathrm{t}(11)=2.21, \mathrm{p}=0.049, \eta^{2}=0.308$, in the NCR condition

\section{Bonus}

- the sense of embodiment did not significantly decrease during the reduplication stage, when the real body was visible to the participant compared to the induction

- $\mathrm{t}(12)=1.44, p=0.174, \eta^{2}=0.148$, average of all conditions

- $\mathrm{t}(12)=0.636, p=0.537, \eta^{2}=0.033$ in the CR condition

- $\mathrm{t}(12)=1.58, p=0.139, \eta^{2}=0.173$, in the NCR condition 


\section{Results}

- Research questions:

$R Q_{1}$ :

"in what body (real or artificial) individuals perceive self-location and with what body self-identification prevails during humanoid embodiment"?

- we did not find evidence of a negative correlation between self-location at the robot and the human body.

- Induction

$\mathrm{CR}(r=-0.246, p>0.05)$

$\operatorname{NCR}(r=-0.198, p>0.05)$

- reduplication

$C R(r=-0.383, p>0.05)$

$\operatorname{NCR}(r=-0.513, p>0.05)$

- self-location in the robot's body in the CR condition was significantly higher during the reduplication $(\mathrm{Mdn}=6)$

compared to the induction $(\mathrm{Mdn}=4.5)$

- $Z=-2.124, p=0.034$ 


\section{Results}

\section{- Research questions:}

\section{RQ2:}

[Does] "having agency influences the perceived sense of self-location and self-identification during robot embodiment and artificial body reduplication compared to the case when there is no agency"?

eliminating control of the robot's body did not significantly decrease the feeling of embodiment compared to having control of it

Induction: $\quad \mathrm{t}(12)=0.744, \mathrm{p}=0.471, \mathrm{n}^{2}=0.044$

Reduplication: $\mathrm{t}(12)=1.619, \mathrm{p}=0.131, \eta^{2}=0.179$

self-location in the robot's body during reduplication was significantly higher in the CR $(M d n=6)$ than in the NCR $(M d n=4.5)$ condition $(Z=-2.555, p=0.011)$

indicator that the lack of agency combined with seeing the real self has a negative effect on the sense of embodiment 


\section{Results: qualitative questionnaire:}

\section{Embodiment}

- P2: "I felt that it was my own body and I had a strong feeling that I cannot define if it is true or illusory experience... It felt like my own body and it was exciting because my mind was not so fast to decide if it is me or not... It was not scary and I thought about it as a continuation of myself"

- P5: "I felt it was me in the mirror"

- P8: "I felt like I had turned into a robot"

- P8: "felt that I was able to control the robot using my own limbs" $(\mathrm{NCR})$

- P11: "I felt somehow that I'm a disabled person" $(\mathrm{NCR})$

Self-Location:

- P4: "it was like if my own mind was inside of the robots head"

- P12: "I felt like I was in the robots body, but only as a guest" 


\section{Results: qualitative questionnaire:}

Bi-location/heautoscopy:

- P1: "It was like I was in three selves: I, but not my body at all, robot, but not in the robot at all, and some place where I cannot say where it was"

- P2: "I felt like being split in two selves"

- P9 "I saw myself standing on one leg and I also felt myself standing on one leg, but my flesh body which normally has a good sense of balance kind of struggled, or should I say I struggled keeping the balance because I was the robot at the same time. It was like being split into two bodies experiencing my balance but not seeing my flesh body balance itself because I was looking through the robot's eyes, my mirror image" 


\section{Results: qualitative questionnaire:}

Disembodiment:

- P5: "I felt it was similar to my body but it was not me"

- P6: "I felt mostly on the robotic body than on mine"

- P7: "I felt that I saw myself through another myself"

- P9: "I saw myself occupying the space, being in space. My body looked weird. Is this how I really look like?"

- P10: "For some moments I had the sensation that my human body was in some sleepy state, and the sensation that I was the robot was stronger"

- P11: "It was like if I was sleeping and seeing myself from another standpoint without any possibility to move"

- P13: "I saw myself but it wasn't actually me. I was seeing somebody else who looks like me ... I wasn't even sure the person was me though, my feeling, my emotion, my thoughts, everything of me was into the robot which was great"

- P8: "I felt the presence of a second being, which in this case was the robot ... I felt like the second individual approaching me" (autoscopic hallucination) 


\section{Summary}

1. Humans are able to experience a sense of embodiment in a non-human looking humanoid robot body

2. When healthy humans are exposed to an artificially induced reduplication of their body, they experience a phenomenon that presents strong resemblance to heautoscopy

3. A healthy human mind is able to (at least subjectively) bi-locate in two different bodies at the same time 


\section{Discussion}

- Further research:

- An interesting question that is still unanswered, is whether the nature of the perceived autoscopic phenomena depends on the induction method

visuo-movement VS visuo-tactile techniques

- Future studies should also assess the enjoyment and pleasantness of the experience compared to that experienced by patients that go through real autoscopic phenomena

- Phenomenoconnectomics

http://asdb.info/ 


\section{Critique}

- Pro:

- Explorative and innovative study

- In situ questionnaires \& Real time and real bodies

- Qualitative data included

- Contra:

- Lack of comparable measurements and data

- multidimensional self-location questions are not really comparable to other studies

- Lack of participants

- Too less questions? Pro or Con? 


\section{Discussion}




\section{References:}

- Aymerich-Franch, L., Petit, D., Ganesh, G., \& Kheddar, A. (2016). The second me: seeing the real body during humanoid robot embodiment produces an illusion of bi-location. Consciousness and cognition, 46, 99-109.

- Hortensius, R. (2017). Social Robotics Journal Club 19.07.17

- http://www.aymerichfranch.com/

- http://asdb.info/ 